\title{
Poniéndonos al día con Gerardo Fulleda León
}

"Soy transgresor. No me gusta el centro ... Me interesa lo que está en la periferia, todo lo que se ve dañado, todo lo que está marginado, sea el hombre, sea el negro, sea la mujer, sean las personas con sensibilidades o peculiaridades diversas. Eso es lo que me interesa porque no soy perfecto."

- Gerardo Fulleda León

Cerardo Fulleda León es uno de los más

$\mathcal{J}_{\text {destacados dramaturgos de Cuba. Pertenece }}$ a una generación de escritores afrocubanos, entre ellos se destacan las poetisas, Nancy Morejón y Georgina Herrera, el dramaturgo Eugenio Hernández Espinosa y el cineasta Sergio Giral, todos centrados en los discursos de la cultura e identidad afrocubana en sus obras. El teatro de Fulleda trata el tema del negro con una visión personal, nacional y universal. Sus piezas se sitúan principalmente en la historia y revelan una riqueza de mitos, ritos y leyendas que acentúan la retención e hibridez de la cultura africana en la diáspora. Su mundo teatral es llena de música, entretenimiento, un lenguaje poético y humor agudo y se ve ejemplificado en todo su quehacer, así como en la obra singular, Chago de Guisa (1989). De esta obra obtuvo el reconocido premio, Casa de las Américas en 1989.

A la edad de 17, escribió su primera obra La muerte diaria (1960), que narra el asesinato

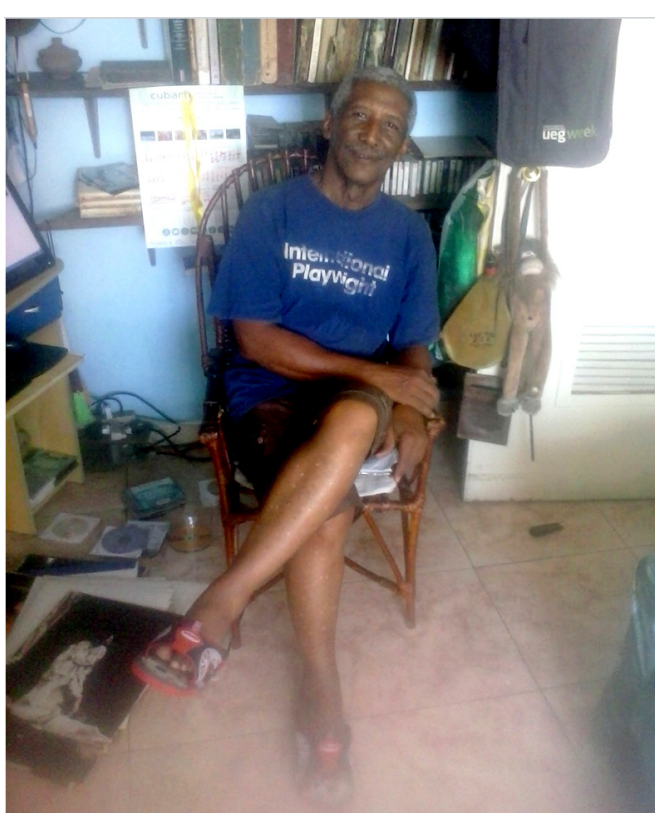

Foto por Darrelstan Ferguson
(1977), cuenta la historia de un niño esclavo con un gran anhelo de libertad y que encuentra el coraje para huir y luego convertirse en cimarrón. Quizá su pieza histórica más sobresaliente, Plácido (1982) trata sobre la vida y la controvertida muerte del poeta mulato cubano, Gabriel de la Concepción Valdés, "Plácido", llevada al cine por Sergio Giral.

"Fulleda es uno de esos artistas que se inscriben en lo que se ha llamado Cultura Popular. Parte su discurso de una contracultura ignorada e interiorizada por el discurso hegemónico, pero que viene reclamando sus fueros. Él es de los que, siguiendo la tradición de un Nicolás Guillén, un Fernando Ortiz o un Alejo Carpentier, entre otros, ha ayudado a devolver, preservar, rescatar y reafirmar la legitimidad de las expresiones de la vida espiritual del pueblo," ha afirmado la investigadora Inés M. Martiatu Terry.

Ahora, a los 75 años de edad y jubilado, Fulleda afirma que dedicó con entrega y pasión, 25 años de su carrera a la Dirección General de la Compañía Teatral Rita Montaner, que mucho le aportaron como experiencia vital. En la actualidad trabaja como Director Artístico en dicha agrupación tras habérselo otorgado el Premio Nacional de Teatro 2014 por la obra de toda la vida.

Atentamente me recibió en su apartamento en La Habana el 30 de agosto y el 1 de septiembre de 2015 para concederme una entrevista en la que hablamos sobre su vida, su carrera teatral, el tema afrocubano, sus por el perjuicio racial. Su pieza para niños, muy estudiada y aclamada internacionalmente, Ruandi 
obras en progreso, y sus planes para el futuro.

\section{Darrelstan Ferguson: ¿Quién es Gerardo Fulleda León?}

Gerardo Fulleda León: Soy un negro santiaguero que nací en 1942 en Santiago de Cuba, y los tíos que me criaron me trajeron a La Habana en 1956, y creo que ya desde niño tenía intención de ser escritor o director de teatro porque me acuerdo de que cuando jugaba con los muchachos de mi calle, en vez de jugar a los bandidos y los buenos, me gustaba más jugar a los héroes y a los mártires que estudiaba en la escuela. Y por supuesto, siempre era el héroe que moría combatiendo, como Antonio Maceo u otros tantos patriotas cubanos, pero específicamente, Antonio Maceo que era una figura que admiraba mucho, al igual que José Martí.

Te puedo decir que también sabía de las películas que no podía ver en el cine, oyendo a los mayores que hablaban de ellas, y eso me despertaba la imaginación; y me ponía a dibujar en mis libretas como una especie de comics. A los que agregaba e inventaba cosas de mi propia inventiva y que los mostraba luego a los demás, a los amigos míos de la escuela por bolas o botones. O sea, que, por lo visto, estaba predestinado para ser escritor o algo parecido.

Y luego, en La Habana, hice disímiles trabajos desde los 14 años, y no pude seguir estudiando. Fui ayudante de mecánica de autos, peón de carpintería, repartí en los automóviles en una esquina céntrica, propaganda de lugares en que vendían efectos eléctricos y limpié zapatos, y así me cogió la Revolución. O sea, no iba a poder estudiar. No tenía condición ni apoyo económico para ello, y había terminado el octavo grado y no podía aspirar a una carrera universitaria.

Y vino la Revolución y me abrió las puertas. Empecé mi primer trabajo estatal, si bien comencé limpiando pisos en la Estación Experimental Agronómica de San Antonio de los Baños. Esa labor me dio un sueldo que no imaginaba, y por las noches pude empezar a estudiar mi bachillerato. Y ahí en el bachillerato y en la Escuela de Artes y Oficios tenía amistades, relaciones con inquietudes culturales, y empecé a escribir poemas y unas cosas, yo las llamaba "diálogos", que eran como unos relatos, pero dialogados; quizá, ahí estaba el germen del teatro, no lo sabía.

Y un día me senté en 1960, frente a la mesa de mi casa donde vivía entonces, y de un tirón escribí mi primera obra para adultos que se llama La muerte diaria. Tenía 17 años, y la mandé al periódico donde publicaban cosas de jóvenes - en un suplemento literario llamado Lunes de Revolución — y me la publicaron. Anteriormente, había mandado unos poemas y me los habían publicado. Y gracias a ello me acerqué así al Seminario de Dramaturgia que había en el Teatro Nacional, y conocí a mucha gente maravillosa, muchos amigos, y así fue cómo empecé mi carrera como dramaturgo y seguí escribiendo poesía. O sea, creo que estaba condenado a ello. Algo decía que tenía que de alguna forma tratar de entender al mundo en que vivía, escribiendo.

DF: Con respecto a lo que hizo la Revolución para la realización de su carrera, ¿en qué manera específica le ayudó? ¿Y cómo describiría su relación con la Revolución como escritor? ¿Percibe algún conflicto de interés entre los dos en cuanto a los temas que usted escoge para abordar, por ejemplo, el perjuicio racial?

GFL: Mira, me dio la posibilidad de dejar de limpiar pisos y de otorgarme una beca para estudiar dramaturgia en el Seminario de Dramaturgia del CNC 1961-1964 donde me daban una mensualidad que en aquel tiempo era considerable para un joven como yo, con profesores como Osvaldo Dragún, Luisa Josefina Hernández, Emilio Carballido, Rolando Ferrer, Alejo Carpentier, Roberto Fernández Retamar, Enrique Pineda Barnet, Wanda Garatti, Rogelio Martínez Furé, Ugo Ulive, Eduardo Robreño, María Teresa Linares y Nestor Raimondi, entre otros más.

El poder asistir, como invitado, a todas las múltiples representaciones escénicas que se daban entonces en diversos teatros de la capital, de martes a domingo; de estrenar mis primeras cuatro obras, tres para títeres y una para adultos; de conformarme como intelectual y poder estudiar una carrera universitaria, sin pagar ni un centavo, ni en libros.

Mira, ha sido publicado todo el teatro que he escrito, bien remunerado, por cierto, se han estrenado la gran mayoría de mis obras. Y sé que algunas han molestado quizás a algunos por la temática tratada como en Plácido, que levantó una polvareda en su estreno. Pero se representó con buen público, se llevó al cine luego y provocó una polémica bastante virulenta, en la cual se manifestaron diferentes puntos de vista contradictorios. Pero hoy no creo 
que nadie pueda negar el valor que tienen como dramaturgia.

El que se hable del perjuicio racial en Cuba, aún molesta a muchos pues quieren no ver los matices de la realidad que vivimos. Por ejemplo—ial fin! —en los últimos meses en la TV nuestra han aparecido locutores y comentaristas negros y negra con gran profesionalidad que nunca antes asomaban el rostro. Pero en el cine y en las telenovelas no aparecen los protagonistas negros, como sí ocurrió en algún momento. ¿Habrá que esperar a que surjan otros Sara Gómez, Maité Vera, Abraham Rodríguez y Sergio Giral para que aparezcan los "negrometrajes," como les llamaban peyorativamente a sus realizaciones unos cuantos detractores?

DF: Y su primera obra, La muerte diaria, ¿había algo que le inspiraba a escribirla?

GFL: La primera obra, La muerte diaria, fue producto de que oía, al comienzo del triunfo revolucionario, comentarios de que los negros no habían participado de forma muy fuerte en la lucha contra la tiranía. Y da la casualidad que cuando tuve mi segunda novia— que era un muchacho, no llegaba a los 14 años, en Santiago de Cuba-el hermano de ella, María, estudiaba en Arte y Oficio, y era un negro y lo mataron los esbirros de la tiranía. Y entonces quise escribir una obra en que el personaje principal veía cómo mataban a un negro compañero de estudios, y él—era un joven blanco-decide alzarse.

Y la obra se llama La muerte diaria por eso, porque habla de esa vida, que vivíamos sin ninguna posibilidad de transformación, de cambio, y de los jóvenes que querían cambiar la realidad, y ese fue el tema. Creo que el problema racial estuvo desde muy joven en mi perspectiva. Tenía mucha conciencia, leía mucho, escuchaba la conversación de los mayores.

Me sentia muy bien como era, pero me interesaba saber por qué ya desde muchacho, allá en Santiago, de 12 o 13 años, supe lo que era la discriminación racial.

DF: La discriminación racial se presenta en otras obras históricas como Plácido. ¿Por qué escoge revisar el pasado en vez de abordar el presente? ¿Quizá algo del presente le provocó a escribir una obra como Plácido?

GFL: No me interesa revisar sino reflexionar. Mira, la Revolución desde su inicio rompió lanzas en contra de la discriminación racial, y creó leyes y tomó medidas para que ésta fuera eliminada de la faz pública de la realidad cubana. Pero, no obstante, los perjuicios de diferente tipo subsistieron en el hombre y la mujer cubana. Estos son más difíciles de extirpar porque subyacen en arquetipos conformados por las mentes, los sentimientos y determinados hábitos que han pasado a integrar nuestra subjetividad y valoración como seres humanos y sociales.

Un poco después de terminar mis estudios en el Seminario de Dramaturgia la problemática de la realidad me fue nutriendo de muchas inquietudes y necesidades, a medida que avanzaba el proceso revolucionario que no satisfacían del todo, en determinados aspectos, a una porción de la población. Leía, me informaba, conocí la obra de Fanon, Marcussi, supe de las Panteras negras y el Black Power, con Angela Davis, y todo el movimiento de Liberación en América Latina y Sudáfrica, y de lo que comenzó a pasar en toda América Latina. Y me di cuenta de que para atrapar la realidad de mi país, en toda su complejidad, tenía que armarme con más potencia y decidí estudiar Historia en la Universidad de La Habana, pues primero tenía que saber bien de dónde había venido para valorar en justeza donde estaba, y llegar a donde quería llegar con mi teatro.

No me interesaba volverme un cronista de mi época, copiarla o retratarla, eso lo hicieron y lo podían hacer muchos, algunos muy bien. Aspiraba, aspiro a más. Y allí, en la Universidad, encontré en los estudios de Historia respuestas a las causas y a los por qué, desde donde habíamos venido a llegar al presente. La historia me dio un arma para, hurgando en el pasado, encontrar formas de reflexionar e interpretar al presente con mayor lucidez. Y mis textos de tema histórico o con temáticas del pasado, siempre, en el sustrato estoy hablando del presente sin translaciones mecánicas. O salvando, las distancias, ¿Vamos a creer que los griegos con sus temas mitológicos y Shakespeare y otros tantos no estaban hablando de su presente en sus obras?

Así surgió Plácido, una reflexión sobre un ser marginado de la sociedad-por pobre, poeta y mestizo - que se hace consciente, aunque sea al final, de su lugar en esta y de todo lo que habría que hacer para transformarla. Un creador que aprende que no hay varitas mágicas para cambiar la existencia que se vive, sino que hay que lograrlo con reflexión, osadía y lucidez; descubriendo y haciendo ver a los demás que 
somos como somos, y cómo podríamos o debemos transformarnos.

Descubrí que la Revolución es un complejo proceso social, cultural y humano que-para su enrequecimiento y transformación ante los embates del tiempo, las necesidades y las deformaciones, de todo tipo, que puedan surgir-requiere reflexiones que ayuden a ver con mayor hondura la realidad y provocar los cambios necesarios para ser mejores.

DF: Su afinidad por los jóvenes afrocubanos se nota en otras obras como Ruandi, Chago de Guisa, Azogue y Betún. ¿Por qué escoge tales protagonistas? ¿Cuál es la relación entre ellos y el tema racial?

GFL: Los escojo porque me tocan, me sensibilizan y hacen que surjan en mí los más encontrados sentimientos y las revelaciones más vitales; porque fui joven como ellos y de diferente manera he tenido retos semejantes y he visto, entre muchos, rasgos y apetencias de ellos, buenas y malas y todos están marcados, para los demás, con el signo de su raza y de su momento histórico.

De haber vivido sus circunstancias hubiera sido como ellos. Y creo que a los que vengan podría servirles de algo el palpar sus semejantes quebrantos, sus anhelos y sus luchas por ser y realizarse, en un mundo mejor. En la creación de todo ellos quizás busqué lograr un tipo de exorcismo personal. Es lo que creo que me corresponde y a la vez me revela mejor: mi interioridad y mi razón de ser.

\section{DF: ¿Contienen elementos autobiográficos} sus obras?

GFL: Aparezco en mis obras, y mi vida y mis problemas por los que he pasado aparecen, pero transmutados. Arthur Miller, un dramaturgo norteamericano, cuando publicó su obra Después de la caída - que dramatiza la historia de un intelectual y su mujer que era una actriz famosa-le preguntaron si esa era su vida con Marilyn Monroe y él dijo, "No, si yo hubiera escrito mi obra sobre la vida de Marilyn Monroe y nuestra relación, habría sido muy aburrida para ustedes. He tomado de muchas mujeres como Marilyn Monroe y de muchos hombres como yo, y les he puesto sus sentimientos y los míos mezclados; y así he hecho literatura dramática, esa no es la historia de Marilyn Monroe y mía”. O sea, ninguna de mis obras es mi historia, pero en todas hay pasajes, sentimientos, pensamientos, problemas, conflictos que he vivido, y por supuesto puntos de vistas muy personales.

Para mí el teatro es un espacio imaginario para la interpretación reflexiva y lúdica de lo sensible de la realidad. Si no hay reflexión y no hay nada lúdico, ¿qué estás haciendo? Estás haciendo lo que hacen a veces por la televisión o por la radio, novelitas que las viste y las olvidaste, en cinco meses nadie se acuerda de ellas. Como decimos al cabo del tiempo: "Ah, ¿cómo se llamaba aquella novelita?”

$\mathrm{El}$ arte, el teatro, es algo más, por consiguiente. No es la vida misma, es algo parecido a la vida, y a la vez tienes que tratar de lograr, encontrar en él el meollo de la realidad, de los conflictos, y no dejarte llevar por las apariencias ni las cosas superficiales que pasan. Porque, por ejemplo, en la Revolución, se han hecho muchas obras en 50 años que han tratado problemas muy puntuales que suceden en un momento y hoy a nadie le interesan, porque son como programas de radio o son periódicos de la realidad, y eso pasa de moda porque no se ha ido profundamente, ni raigalmente y con intensidad. Detrás de todo eso, hay que ver al ser humano que está hablando, desangrándose y viviendo. A mí me gusta el ser humano, sobre todo, y el ser humano es algo más que la circunstancia que vive.

DF: Para mí, sus obras parecen filosóficas, políticas, culturales, y aún psicólogas, todos a la vez. ¿Cómo definiría su obra completa, su estilo de escribir, su "identidad de escritor"?

GFL: Eres muy amable. De todo ello me nutro, indudablemente, pero no creo que pueda decir una verdad más cierta que un filósofo, tener más poder para transformar la sociedad que un político, ser más necesario que algún dirigente cultural, ni ayudar mucho a canalizar sus problemas síquicos a un paciente como un psicólogo.

Lo mío es sensibilizar, conmover, entretener y ayudar al espectador a reconocer en sí lo que él también puede y podría ser, ayudarme y ayudar a los demás a ser mejores. Mi obra es una indagación muy personal de los tiempos que han sido y de los que vivo. Alguien que quiere y hace todo lo posible por encontrar una definición mejor, un futuro promisorio.

\section{DF: ¿Diría que escribe con una agenda?}

GFL: Si reincidir en determinadas temáticas una y otra vez, si ahondar en situaciones que desde disímiles puntos tocan mi sensibilidad, si hurgar en caracteres e intensidades que me obligan a reconocer 
a los demás y a mí mismo, si voy de la historia a la realidad contemporánea, si no ceso en descubrir nuevas probabilidades, develarme nuevos retos e intentar ir a nuevos alcances, gracias a la poesía de la existencia, sí, entonces tengo una agenda como escritor.

Creo que mi teatro se nutre de tres vertientes:

1. La histórica. A mí me interesa mucho la historia porque creo que nos ayuda a saber de dónde vinimos y por qué las cosas son como son y a dónde estamos y a dónde podemos ir.

2. Las leyendas, los mitos, los ritos. Porque todo eso aporta una riqueza y una sabiduría que está regada, diseminada en nuestras sociedades, en la cultura popular tradicional pero no justamente valorada, a veces, y me interesa de alguna manera integrarlos a mi discurso escénico.

\section{El humor, el entretenimiento, la música, la vida.}

Creo que tanto en la vida que llevamos como en el arte necesitamos de todo ello.

Escribo porque hay cosas que no me explico de la realidad, que no entiendo a cabalidad, o porque no estoy de acuerdo con ellas, y trato de alguna forma de saber por qué son así, y cómo esas cosas se pueden transformar o se pueden cambiar en mejores.

No escribo para decir nada, sino para descubrir cosas, cosas de los demás y de mí. Particularmente, soy menos importante, lo importante son los demás, los otros, escribo sobre los otros, aunque a veces a los otros les transfiero sentimientos que pasan por mí; pero los demás, son los que más me interesan, sobre todo el mundo de los jóvenes, de los niños, de las mujeres, de todo lo que está al margen. No soy del centro, nunca voy a ser del centro, pero me interesa todo lo que está al margen, y al margen, de cierta manera, todavía en nuestra sociedad están la mujer y el negro, y nuestra cultura popular es vista por muchos y considerada como algo inferior.

DF: Usted mencionó en un artículo en Cubahora que le interesa arreglar este mundo. ¿No diría que su agenda es "arreglar" el problema de la marginalización de los afrocubanos? ¿Y cómo cree que sus obras buscan alcanzar esto?

GFL: Prepotencia, entendido literalmente. Hablaba de ayudar a arreglar la interpretación del mundo, desde lo que creo. No soy el indicado para arreglar algo que no podamos conseguir si no es con la anuencia de todos. Más que arreglar diría avizorar, ayudar a transformar mentalidades y actitudes, sensibilizar, despertar inquietudes, abolir rechazos y fronteras, encontrar esa esquiva y ansiada plenitud, no con discursos sino con acciones, sentimientos y la sensibilidad que puede despertar desde la poética escénica ese acto de revelación que nos ofrece el arte.

\section{DF: ¿Qué significa ser “afrocubano”?}

GFL: Significa, antes de todo, un orgullo y una conciencia. Estuve en África, en Ghana hace años. Fui a Mount Cape y a otro lugar que era como un laberinto, por debajo de la tierra a donde llevaban a los esclavos encadenados y se morían muchos en el camino. Los llevaban como cerca de seis kilómetros por debajo de la tierra para meterlos en los barcos negreros, y no me atreví a pasar: me dio horror, me dio mucho espanto, y esa conciencia quiero que los negros, y las negras, sobre todo, del mañana y de mi país y de todo el mundo lo tengan; que sean mejores y sean más conscientes de su fortaleza, de su historia, de su valentía, de todo lo que han sufrido, de todo lo que hemos padecido, y estén orgullosos de ser lo que somos. Eso es lo que me interesa. Me siento muy contento, nunca he querido ser de otro color, nunca he pensado ni he soñado en decir "si fuera blanco, rubio y fino porque ellos tienen el poder". Soy negro, soy valioso y único.

\section{DF: Entonces, escribe para los afrocubanos, ¿no?}

GFL: Para ellos, para nosotros y para los demás también, para sensibilizarlos también, porque creo que debemos tener conciencia de nuestra identidad, y para que los otros aprendan a respetarnos y a considerarnos, porque no vivimos-ni quiero vivir-en un mundo completamente negro, ni en un mundo completamente blanco. Quiero vivir en un mundo en que nos entendamos y nos aceptemos todos. No me gusta la palabra tolerancia. Ya no creo en la tolerancia, no es suficiente, no soporto la tolerancia-lástima, ninguna quiero-reclamo y quiero la aceptación. La tolerancia es una lástima disfrazada, es como decir "Pobrecito. Tolérame que te soporto, porque soy mejor".

DF: ¿Por qué es importante que escriba sobre la cultura afrocubana?

GFL: Porque pertenezco a ella, soy parte de ella, y creo que es muy importante porque hay muchas cosas todavía que decir sobre lo que somos, lo que 
sentimos, y a lo que aspiramos, y lo que necesitamos. A mí me interesa escribir, sobre todo, lo que está al margen. En muchas sociedades todavía el negro, y sobre todo la mujer negra, están al margen. No ocupamos el carácter representativo que deberíamos ocupar en la sociedad y por eso creo que es importante que uno se detenga a analizar, a estudiar y a mostrar las necesidades, las apetencias, los criterios, los sentimientos, los anhelos, los aportes y también las frustraciones de nuestra raza.

DF: ¿En qué manera cree que sus obras han impactado al canon de la literatura afrocubana?

GFL: No te lo puedo decir. Esa es una labor de los críticos. He intentado de alguna forma dar mi visiónmi punto de vista-más que una filosofía, y he tratado de alguna forma de hacerlo que sea una cosa atractiva, rica, profunda, reflexiva y a la vez divertida.

\section{DF: ¿Y en general cómo los críticos han} recibido sus obras?

GFL: Tengo muy buenos críticos. Por ejemplo, en Jamaica Paulette Ramsay ${ }^{1}$ y Joseph Pereira ${ }^{2}$, y en Inglaterra el profesor, Conrad James ${ }^{3}$, que ha escrito sobre mis obras y no me puedo quejar. En los Estados Unidos, Inglaterra, Suiza, Brasil, y en otros sitios tengo también estudiosos de ellas, profesores y profesoras que están interesados en ella. Y en Cuba, por supuesto, tengo analistas como Inés María Martiatu ${ }^{4}$, Nancy Morejón ${ }^{5}$, y a otros que se han detenido a valorarlas.

Normalmente, hay una parte de la crítica a la que le parece que hago teatro afrocubano, o sea "afrocubano" entre comillas, y que hago un teatro que es un teatro sin trascendencia-eso lo piensan algunos_-"porque toca otra vez: el problema del negro". Y claro, casi todos ellos son blancos. Y entonces, por consiguiente, no se detienen en mi interioridad, y me tildan de "afrocubano".

No estoy muy de acuerdo con el término afrocubano porque nadie dice de Abelardo Estorino, que era un gran dramaturgo cubano, blanco por supuesto; o de Virgilio Piñera, que era otro dramaturgo, el más grande que hemos tenido; o Héctor Quintero, que es un inmenso comediante cubano; no dicen de ellos que eran "hispanocubanos", dicen que son cubanos. Entonces, el "afrocubano", cuando ellos lo utilizan, lo utilizan como una forma discriminatoria.

Soy un escritor cubano que toca los temas que me corresponden, ¿Por qué debo escribir como los blancos, por qué? Y mis personajes son blancos y negros, reitero: no vivo en gueto. En Cuba no existen los guetos como existieron en los Estados Unidos, y entiendo más el término afrodescendiente. En los Estados Unidos los negros vivían en guetos, vivían separados, pero en Cuba los negros nunca hemos vivido separados, a no ser en tiempos de esclavitud. Los blancos fueron los que se apartaron en la llamada República. Vivían en los barrios de los blancos con dinero, pero en todos los demás barrios, vivimos blancos y negros juntos. No hay un barrio solamente de negros en mi país.

En ese sentido, eso me parece que fue algo muy importante para el movimiento de los negros norteamericanos, igual que posteriormente la obra de Fanon, la función de Fanon. Es un hombre imprescindible. En su libro, Piel negra, máscara blancaigenial! - y el otro, Los condenados de la tierra - ies un libro increible! - pero él vivía en una subyugada nación donde existían poderes racistas y guetos; y por eso respeto y considero al movimiento de los Black Power.

El perjuicio racial existe aún en Cuba, pero es soterrado, callado, solapado, a veces miserable, pero se siente, se palpa todavía. Se ha avanzado mucho pero aún se manifiesta. Todavía cuando alguien dice, "No, él hace teatro afrocubano", yo sé que me está discriminando porque no dicen de los otros que ellos hacen teatro "hispanocubano". Entonces, ¿por qué a mí? ¡Carajo! ¡Qué diablos me tienen que poner el sambenito de afrocubano!

Estoy muy contento de ser afrodescendiente. Ese es un término con el que más congenio-_Cuál ser vivo no lo es? - y cuando me levanto por las mañanas y me veo ante el espejo, lo primero que descubro es un ser humano; lo segundo un hombre; el tercero un negro; cuarto, entro en mi interioridad - cubano - y eso es algo que es interno. ¿Cómo no escribir desde ese punto de vista?

DF: Es bastante interesante ese orden: humano, hombre, negro y cubano. ¿Diría que sus obras intentan mostrar esta imagen del afrodescendiente? ¿Opina que la lucha de los afrocubanos para verse y aceptarse como “auténticamente cubano" ha cumplido su meta, o continúa?

GFL: Más que mostrar, indagar en el afrodescendiente que soy, en lo que somos y redescubrirnos a cada paso, para transformarnos 
con el tiempo. La lucha continúa, es un lento y largo proceso con logros y altibajos como cada lucha. No es cuestión de una generación sino de sucesivas con acciones, logros, alcances y recaídas y vueltas a la contienda, hasta que un día se logre la finalidad. No sé lo que falta, pero continuará y se alcanzará el logro, algún día.

DF: ¿Considera que el uso del término "afrocubano", con respecto a sus obras es un tipo de límite?

GFL: No un tipo de límite siempre, sino depende de quién me cataloga porque sirve para estudiarme y para ensalzarme, pero lo usan también para denigrarme y opacarme. Algunos lo usan para eso. "Él tiene unas obras de negritos esclavos, mira lo que trata, es un poeta esclavo". Soy "racista" para ellos, probablemente, porque trato de lo que soy. No me molesta el término siempre, sino según de quién venga, según de quién me clasifica.

Si tú lo usas, tú no me estás limitando, tú me estás singularizando, pero si lo usa alguna otra gente, en muchas ocasiones, para aminorarme. "Él es un poeta afrocubano, un dramaturgo afrocubano, no un dramaturgo cubano-_afrocubano'-él no es como nosotros, iqué cubano!" Carpentier es cubano, ¿por qué no dicen eso de Carpentier que hizo El reino de este mundo, que hizo dos novelas que tienen personajes negros? Discriminación.

Entonces, ese es el problema, por eso es muy molesto, depende de quién mira. Algunos críticos a los que no intereso. Bien. Ya vendrán a los que interesé. ¿Quién me iba a decir que a los 32 años de estrenado Ruandi iba a ser un éxito en Alemania y traducirse al inglés, al italiano y al francés?

DF: ¿Hay algún escritor dentro de Cuba o de afuera que le inspira?

GFL: José Marti, Nicolás Guillen, por supuesto, Alejo Carpentier, Lydia Cabrera. De afuera, Mark Twain, Lewis Caroll, Saint-Exupéry, Dickens, Gogol, Antón Chéjov, Emily Dickinson, Virginia Woolf, y otros tantos que harían la lista interminable.

Soy muy amante de la literatura, sobre todo de la poesía, pero leo muchas novelas, muchos cuentos: La cartuja de Parma de Stendhal me encanta; La guerra y la paz de Tolstoi; Los hermanos Karamazov de Dostoyevsky; Fanon, es alguien para mí muy importante; Césaire, como poeta y como ideólogo; la Biblia. Hay muchas cosas que me han conformado, y de todo cojo, chupo, trago para llenarme un poco.

DF: ¿Cómo es su relación con los otros escritores afrocubanos?

GFL: Es excelente. Creo que un hombre no es una isla y necesita de personas que tengan los mismos intereses o inquietudes para de alguna manera provocarse, porque es muy necesaria la visión del otro. A mí me interesan más los otros que yo mismo. Por ejemplo, casi nunca me releo porque cuando lo hago me doy cuenta de que podía haber hecho esto así o de otra forma, y no quiero pasar por eso. Me gusta leer a los demás, mi gran disfrute es leer a los demás.

Y en mi generación - tengo una generación maravillosa, no solamente de dramaturgos sino también de poetas y escritores-hay poetisas tan intensas como Excilia Saldaña, una gran amiga y ya desaparecida; Nancy Morejón, una excelente poetisa y además ensayista y crítica y de obra muy sólida; Georgina Herrera, una poeta singular, con una autenticidad y unos valores únicos; Isel Rivero, que hace años vive fuera del país pero sigue siendo muy creativa; Miguel Barnet, que es un singular poeta y novelista, tiene un trabajo cumbre: Biografía de un cimarrón que nos sirve a nosotros mucho; y otros más, como Lina de Feria, que es una poetisa santiaguera penetrante y vital.

Eran los compañeros de mi grupo, de El Puente, y también por suerte contamos con la cabeza de un sabio eminente, que además de ser poeta es etnólogo e historiador, Rogelio Martínez Furé.

Entre los dramaturgos al primero que citaré: Eugenio Hernández Espinosa, un gran dramaturgo, tiene obras esplendidas y clásicas como María Antonia, La balsa y Mi socio Manolo; René Fernández Santana, que ha escrito obras para niños con el tema afrocubano que es muy importante; Jesús Gregorio, un dramaturgo que fue muy exitoso; José Milian, que no es su tema principal el tema afrodescendiente pero que aprovecha la cultura popular con mucha chispa y mucho ingenio; un brillante autor de farsas antológicas como Nicolás Dorr; y, quizás uno de los más trascendentes creadores de mi generación, Tomás González, dramaturgo, guionista, poeta, pintor, cantante y gran maestro escénico.

\section{DF: ¿Y entre los narradores?}

GFL: De los narradores: Manolo Granados, fallecido ya, escribió una novela como Adire y el tiempo 
roto y libros de cuentos muy personales en que por su procedencia humilde y racial se expresó con una capacidad de ingenio y fabulación muy grande, hizo una obra muy importante. En mi generación hay una mujer que para mí es una excepcional narradora que escribió también importantes obras de teatro, Ana María Simo.

Hay unos que no tienen temas sobre los afrodescendientes, pero son poetas importantes de mi generación: José Mario Rodríguez, el fundador de las Ediciones del Puente con Isel Rivero; está también Reinaldo García Ramos, un poeta que ha logrado un equilibrio y una forma de representación lírica muy válida.

No quiero olvidar a Guillermo Cuevas Carrión, que sepa, tiene sólo un libro que publicó entre nosotros, Ni un Si, ni un No, pero que tiene ingenio, y esa cosa, ese demonio de los creadores verdaderos. Y por ahí está Santiago Ruiz, un dramaturgo que escribe también teatro y que ha tocado el tema afrocubano que vive en Nueva York, al igual que Pedro Monge, que lo han hecho atinadamente.

Hay unos dramaturgos que no son de mi generación que en alguna forma han tocado el tema, están Rolando Ferrer, que fue un profesor, un amigo y alguien muy trascendente; Carlos Felipe, que tiene una obra magistral, Réquiem por Yarini en que la protagonista es una mujer negra; y el dramaturgo cubano más reconocido internacionalmente, José Triana.

\section{DF: ¿Tiene en progreso alguna otra obra?}

GFL: Sí, ahora estoy escribiendo una obra que se llama Adoración confesa por Marilyn Monroe ${ }^{6}$. Es la historia de tres personajes: una actriz negra; su esposo que es escritor de la radio, mulato; y un blanco, mayor que ellos, que viene con la Caravana de la Revolución desde Santiago de Cuba y todo ocurre durante cinco décadas en un mismo lugar en un nightclub que está en los altos de un edificio en El Vedado. Y los conflictos tienen de fondo sucesos que considero muy importantes para ellos en esas cinco décadas que hemos pasado, pero conflictos que no están nombrados aunque inciden en los personajes y sus conductas. Nunca se van a citar o nombrar en la obra los hechos en sí, sino las repercusiones que han tenido sobre ellos. La gente podrá entender lo que está pasando en qué momento, pero no se van a explicitar nunca escénicamente.

Por ejemplo, la primera escena ocurre la noche antes de los misiles de 1963 en que al día siguiente podía desaparecer Cuba porque los Estados Unidos nos iban a atacar. No se habla tampoco de la Unión Soviética, sino se habla de la angustia, anhelos y actitudes que los personajes tienen y todo lo que ellos quieren de la existencia porque mañana podría ser el último día de sus vidas. No se va a decir cosas históricas, ni a dilucidarlas, pero se va a oír por cada época una canción cubana que más o menos va ubicando la época.

DF: ¿Cree que hay una nueva contribución que puede hacer con una nueva obra en cuanto a la Cuba actual o en relación a la Cuba del futuro?

GFL: Sí, sobre eso, casualmente, es la obra que estoy escribiendo. Creo que estoy listo para una nueva acometida, y voy a tratar de llevarla al máximo. Tengo la suficiente insatisfacción y el suficiente goce a la vez con la vida para emprender nuevas aventuras y correr nuevos riesgos. Eso es lo más importante. Hace mucho rato que no tengo ningún miedo a los nuevos proyectos, el único miedo que podría tener es algo inevitable, y eso cuando sea, será. Quiero seguir mientras creando, quiero experimentar, quiero buscar, encontrar y lo voy a seguir haciendo. Es un proyecto muy ambicioso y renovador que está exigiendo mucho de mí.

\section{DF: ¿Qué opina de la nueva relación entre Cuba y los Estados Unidos?}

GFL: Es algo de lo que ambos países nos estábamos perdiendo. Cuba era el mercado más cercano que tenía los Estados Unidos y vicevera, y creo que los Estados Unidos nos proveyeron de muchas cosas durante mucho tiempo, al igual que nosotros a ellos. Creo que no se puede ser enemigo de alguien durante tanto tiempo y vivir tan cerca el uno del otro, y que este paso es necesario, es un sosiego. Lo que no quiere decir que los americanos vayan a cesar de su interés de alguna forma de ser imprescindibles e incidir en el desarrollo de los acontecimientos de Cuba.

Pero ya será de otra forma. No creo que vayan a colonizarnos con los McDonald's y la CocaCola y todas esas cosas, para mí frívolas, no van a engolosinar a una gran parte de la población, por lo menos a mí no. Y el turismo no es necesario a ambas partes.

Fidel Castro Ruz creó, indudablemente un movimiento en toda América Latina con su proceder 
y con nuestra Revolución, al igual que Camilo, el Che y todos los que lucharon en La Sierra. Para mí es un hombre fuera de serie, un genio. Raúl es un gran estadista, un hombre indudablemente de transición, pragmático y que ha entendido la necesidad de entablar buenas relaciones para el mejoramiento mutuo, no solamente para adquirir en los Estados Unidos las otras cosas que necesitamos más baratas que lo que nos cuesta ahora por el bloqueo. El bloqueo creo que es algo infame; un horror, el haberlo padecido y ha estado obstruyendo la forma de vivir de los cubanos durante mucho tiempo. Creo que aún lo es. Obama y Raúl van a pasar a la historia como esos dos hombres, sin borrar el pasado, trataron de mirar hacia el futuro, y espero que sea para beneficio de ambas naciones; pero espero que esto no se convierta en Miami. Creo que no se va a convertir en Miami, que es un lugar hermoso, pero que a mí no me dice mucho en lo cultural, lamentablemente.

\section{DF: ¿No le interesaría incorporar lo político en una nueva obra?}

GFL: No me interesaría. La política es una cosa muy social, muy real y a veces creo que puede manchar o afear la literatura. Aunque en última instancia, quizás todo lo que haga es "política", en otro sentido más visceral pero no tengo por qué explicitarla en mi obra creativa; la bota del militar no tiene que aparecer en una obra para saber que sea militar un personaje, decía Chéjov. Entonces, no es necesario. No voy a hacer teatro político, aunque... ¿quizás lo hago?

Mira, tengo un viejo sueño de hacer una obra de teatro-que a lo mejor no voy a cumplir — que es coger a 12 personajes de los que asaltaron el Moncada y hacer una obra sobre el Moncada; porque hay una heroína que luchó en el Moncada que se llama Haydée Santamaría, a la que admiro profundamente, que fue la que fundó la Casa de las Américas. Y me gustaría hacer una obra sobre eso, sobre el asalto del Cuartel Moncada desde su visón de esa epopeya y desde mi perspectiva humana. Fue un momento y un hecho trascendente en nuestra historia. Atesoré durante mucho tiempo mucho trabajo sobre el tema, y en particular, todo lo que ella escribió, pero no sé si la podré escribir la obra. Tengo que escribir al menos dos o tres obras más que me interesan, como una que se llama Peregrinaje al Cobre ${ }^{7}$. Pero nadie sabe las vueltas que va a dar la vida.

Y si tú quieres saber algo, no me considero... "revolucionario"-mira, la palabra "revolucionario" no es una palabra que uno se debe asignar a sí mismo, eso lo designan los demás por lo que tú haces, produces o creas. Entonces, no tengo un carné del partido, no soy militante del partido, sin embargo, agradezco mucho al proceso revolucionario; lo he defendido y lo defenderé y— sin excluir la críticatrato de alguna forma de que todos los que vivamos dentro de él, seamos mejores, pensemos mejor, y actuemos mejor. Si esto es ser revolucionario, que me lo digan los demás, pero ya no me preocupo con eso. Soy transgresor. No me gusta el centro, reitero. Me interesa todo lo que está en la periferia, el centro no me interesa y ahí cae la palabra política. Me interesa lo que está en la periferia, todo lo que se ve dañado, todo lo que está marginado, sea el hombre, sea el negro, sea la mujer, sean las personas con sensibilidades o peculiaridades diversas. Eso es lo que me interesa porque no soy perfecto.

\section{DF: ¿Qué significa ser "transgresor" en} el contexto del socialismo cubano, de la Revolución cubana? ¿En qué manera diría que lleva a cabo transgresión como dramaturgo?

GFL: Ser transgresor es: tener siempre alertas las antenas a todo lo trascendente e importante que ocurre en mi realidad y el mundo; no conformarme con lo alcanzado y tratar de ir más allá y lograr concretizar las aspiraciones y los sueños de una sociedad mejor y más equitativa; no repetir fórmulas creativas que sirvieron pero que ya son obsoletas para la creación contemporánea; no asentarme en lo logrado y crear nuevos retos, voces y visiones a la hora de recomponer mi realidad en una obra de teatro; correr los riesgos con osadía y verdad a la hora de enfrentarme ante la hoja en blanco.

\section{DF: ¿Está satisfecho con sus obras de teatro?}

GFL: Satisfecho no es la palabra sino agradecido. Agradecido por lo que me han proporcionado y por lo que me han ayudado a conocerme más a mí y a los demás.

DF: ¿Cómo se siente al saber que algunas de sus obras se han llevado al cine?

GFL: Muy contento pero consciente de que el cine es otra cosa. Soy muy amante del cine y veo mucha TV cuando no leo y escribo. Todo eso me ha enseñado a ver los límites y las posibilidades del teatro y cómo enrarecer al teatro con mecanismos que aparentemente, son cinematográficos o literarios, 
pero le pueden aportar el teatro. Eso lo aprendí con Plácido y lo agradezco mucho.

Ahora mismo tengo el guión de Ruandi $i^{8}$, de la cual que quieren hacer en los Estados Unidos una película. Es una estructura diferente a Ruandi teatral, pues tiene otros aportes y estructuras en las cuales no pensé y me parece muy bien. El cine es el cine, el teatro es el teatro, la literatura es la literatura, y no se puede pretender la fidelidad del calco. La fidelidad es una fidelidad a las esencias, a las cosas centrales, no a las estructuras. Las estructuras tienen que cambiar, y algunas tienen que perderse y transformarse en otra cosa según el medio expresivo.

DF: Si pudiera cambiar algo de su carrera, ¿qué sería y por qué?

GFL: ¿Quieres que te sea franco? Me hubiera gustado haber escrito más poesía de la que he escrito.

DF: ¿Cómo quisiera ser considerado después de la muerte?

GFL: Si alguien algún día me considerará un poeta dramático, dondequiera que esté, me voy a sentir muy satisfecho y muy agradecido.

\section{DF: Muchas gracias, Señor.}

GFL: Muchas gracias a ti.

\section{Notas}

1. Paulette Ramsay es Catedrática de Literatura Hispanoamericana en The University of the West Indies, Mona Campus. Se especializa en la investigación de la cultura afro-latinoamericana y ha estudiado la vida y las obras de Gerardo Fulleda León en publicaciones como, "Conversación con el Dramaturgo Afro-Cubano Gerardo Fulleda León" y "On Page and On Screen: An Examination of Gerardo Fulleda León's Plácido (1982) and its Cinematic Representation."

2. Joseph Pereira es Vicedirector Retirado de The University of the West Indies, Mona Campus. Ha realizado investigación destacada y extensiva en la cultura afrocubana y particularmente, en el teatro cubano. Trata las obras de Gerardo Fulleda León en su ensayo "(Sub) Versions of the Cuban State: The Plays of Gerardo Fulleda León."

3. Conrad James es Doctor de Estudios

Latinoamericanos en University of Birmingham. Su campo de investigación es la producción cultural en el Caribe, particularmente, en Cuba y la República Dominicana. Ha editado dos libros de ensayos que tratan este campo: The Cultures of the Hispanic Caribbean (2000, editado con John Perivolaris) y Writing the Afro-Hispanic: Essays on Africa and Africans in the Spanish Caribbean (2012).

4. Inés María Martiatu falleció el 3 de julio de 2013. Fue crítica cultural, investigadora teatral, ensayista, y narradora que hizo una inmensa contribución a la cultura afrocubana. Se otorgó la Distinción por la Cultura Nacional en Cuba. Ha estudiado Gerardo Fulleda León en la publicación Resistencia y cimarronaje: Teatro de Gerardo Fulleda León.

5. Nancy Morejón es poetisa, periodista, crítica literaria y teatral, ensayista, y traductora cubana. Actualmente, es la Directora de la revista Unión. Ganadora del Premio de la Crítica en 1986, 1997 y 2000 por sus libros, Piedra pulida, Elogio y paisaje, y La Quinta de los Molinos, respectivamente.

6. Previamente a la publicación de esta entrevista, Gerardo Fulleda León comentó que Adoración confesa por Marilyn Monroe todavía es una obra en progreso.

7. Previamente a la publicación de esta entrevista, Gerardo Fulleda León confirmó que Peregrinaje al Cobre todavía es una obra en progreso.

8. Previamente a la publicación de esta entrevista, Gerardo Fulleda León comentó que Ruandi se ha traducido al inglés para ser publicada en los EUA.

\section{Agradecimientos}

Estoy altamente agradecido al Señor Gerardo Fulleda León por la oportunidad brindada en la realización de esta entrevista. Además, me gustaría agradecer a la Señora Martha Esmeralda Nunes, Instructora de Español en The University of the West Indies, Mona Campus, por haber colaborado en la revisión de esta transcripción. En este proyecto he aprendido que ningún hombre es una isla.

\section{Darrelstan Ferguson The University of the West Indies, Mona Campus}

